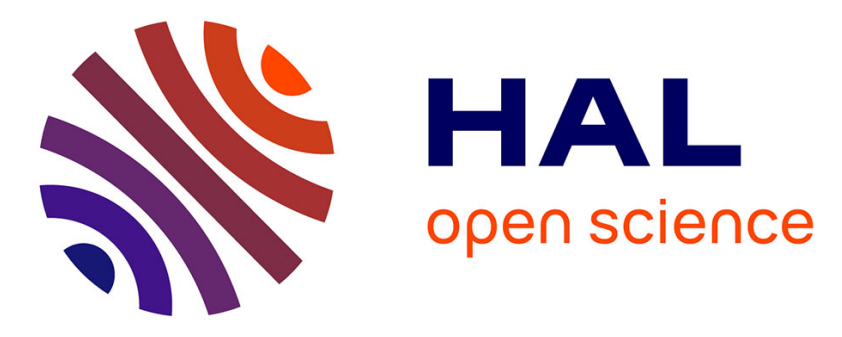

\title{
Implementation of a molecular tumor board at a regional level to improve access to targeted therapy
}

Heloise Bourien, Alexandra Lespagnol, Boris Campillo-Gimenez, Ingrid Felten-Vinot, Jean-Philippe Metges, Romain Corre, Thierry Lesimple, Cedric

Le Marechal, Lise Boussemart, Solène-Florence Kammerer-Jacquet, et al.

\section{To cite this version:}

Heloise Bourien, Alexandra Lespagnol, Boris Campillo-Gimenez, Ingrid Felten-Vinot, Jean-Philippe Metges, et al.. Implementation of a molecular tumor board at a regional level to improve access to targeted therapy. International Journal of Clinical Oncology, 2020, 25 (7), pp.1234-1241. 10.1007/s10147-020-01661-6 . hal-02565097

\section{HAL Id: hal-02565097 \\ https://hal-univ-rennes1.archives-ouvertes.fr/hal-02565097}

Submitted on 11 Jun 2020

HAL is a multi-disciplinary open access archive for the deposit and dissemination of scientific research documents, whether they are published or not. The documents may come from teaching and research institutions in France or abroad, or from public or private research centers.
L'archive ouverte pluridisciplinaire HAL, est destinée au dépôt et à la diffusion de documents scientifiques de niveau recherche, publiés ou non, émanant des établissements d'enseignement et de recherche français ou étrangers, des laboratoires publics ou privés. 


\section{Implementation of a molecular tumor board at a}

\section{regional level to improve access to targeted therapy}

AUTHORS: Héloïse BOURIEN ${ }^{1}$, Alexandra LESPAGNOL ${ }^{2}$, Boris CAMPILLO-GIMENEZ ${ }^{1}$, Ingrid FELTEN-VINOT ${ }^{3}$, Jean-Philippe METGES ${ }^{3,4,5}$, Romain CORRE $^{2,5}$, Thierry LESIMPLE $^{1,5}$, Cédric LE MARECHAL ${ }^{4}$, Lise BOUSSEMART ${ }^{2,6}$, Solène-Florence KAMMERER-JACQUET ${ }^{2}$, Edouard LE GALL ${ }^{3}$, Florent DENOUAL ${ }^{2}$, Marie DE TAYRAC ${ }^{2}$, Marie-Dominique GALIBERT ${ }^{2,6}$, Jean MOSSER $^{2,6}$, Julien EDELINE ${ }^{1,5}$

1- Centre Eugene Marquis, Unicancer, Rennes, France

2- CHU Pontchaillou, Rennes, France

3- Pôle Régionale de Cancérologie de Bretagne, France

4- CHU Brest, France

5- ARPEGO (Accès à la Recherche Précoce dans le Grand-Ouest) network

6- Université Rennes, CNRS, IGDR, UMR 6290, Rennes, France

$\mathrm{HB}$ and AL contributed equally, JM and JE contributed equally to this work

Corresponding author:

BOURIEN Héloïse

Centre Eugene Marquis, Unicancer, Rennes, France

Mail address: h.bourien@rennes.unicancer.fr

Phone number: 00332.21.07.17.66 


\section{ABSTRACT:}

BACKGROUND: With the development of precision oncology, Molecular Tumor Boards (MTB) are developing in many institutions. However, implementation of MTB in routine clinical practice has still not been thoroughly studied.

MATERIAL AND METHODS: Since first drugs approval for targeted therapies, patient tumor samples were centralized to genomic testing platforms. In our institution, all tumor samples have been analyzed since 2014 by Next Generation Sequencing (NGS). In 2015, we established a regional MTB to discuss patient cases with 1 or more alterations identified by NGS, in genes different from those related to drug approval. We conducted a retrospective comparative analysis to study whether our MTB increased the prescriptions of Molecular Targeted Therapies (MTT) and the inclusions of patients in clinical trials with MTT, in comparison with patients with available NGS data but no MTB discussion.

RESULTS: In 2014, 86 patients had UGA, but the results were not available to clinicians and not discussed in MTB. During the years 2015 and 2016, 113 patients with an UGA (unreferenced genomic alteration) were discussed in MTB. No patients with an UGA were included in 2014 in a clinical trial, versus 2 (2\%) in 20152016. 13 patients with an UGA (12\%) were treated in 2015-2016 with a MTT whereas in 2014, no patient $(\mathrm{p}=0.001)$.

CONCLUSIONS: In this retrospective analysis, we showed that the association of large-scale genomic testing and MTB was feasible, and could increase the prescription of MTT. However, in routine clinical practice, the majority of patients with UGA still do not have access to MTT. 


\section{INTRODUCTION:}

After several decades during which the treatment of metastatic cancers was based on the use of cytotoxic drugs, personalized medicine with targeted therapies has now become everyday practice. Precision medicine in oncology mostly refers to the selection of one drug targeting one or more molecular pathways specifically altered in the patient's tumor. In the early 2000s, new standard of care have been developed. For example, the BRAF-inhibitor (vemurafenib) used initially alone and later in association with MEK-inhibitor have improved clinical outcomes in patients with stage IV BRAF V600E-mutated melanoma (1-3).

Evolutions in DNA sequencing technology allowed using genetic information in clinical routine. With the next generation sequencing (NGS) large genomic regions can be analyzed in order to detect clinically relevant mutations. Since ten years, the cost of NGS has declined rapidly; the economic analysis conducted in the MOSCATO trial, reports that molecular diagnosis requires only $6 \%$ (i.e $2396 €$ ) of the total cost of molecularguided therapy (4).

To test personalized medicine in different cancers, some trials have emerged. The MOSCATO 01 trial (5) evaluated the clinical benefit of a genomic analysis. Only $7 \%$ of patients who had a molecular profile, had a PFS2 (progression-free-survival 2), defined as PFS on targeted therapy, 1.3 fold longer than PFS1, defined as PFS on prior treatment. The SAFIR-01 trial (6) proposed to identify driver mutations to guide treatment. Only $28 \%$ of patients were treated with matched targeted therapy in this trial. The SHIVA trial (7) was designed to propose a treatment algorithm to define criteria for the prioritization of molecular alterations that could be targeted. This trial was negative; the primary end point defined as an increase of PFS of $40 \%$ at 6 months in the experimental group, was not achieved. Numerous challenges arise from these studies, such as access to drugs. These studies involved heavily pretreated metastatic patients; however, identifying molecular alterations in earlier stages could lead to propose more frequently targeted therapies.

With the development of personalized medicine, Molecular Tumor Boards (MTB) are becoming fundamental and are created in many institutions (8-18).However, the benefit of MTB in routine clinical practice has still not been thoroughly studied, as most data from MTB emerged from single center institutions, with selected patients. In Rennes, all tumors requiring the screening of genomic alterations, used as biomarker for prescription of Molecular Targeted Therapies (MTT) were analyzed by NGS since 2014, with a panel of more than 30 genes. One year later, in 2015, we established a MTB involving the Rennes' University Hospital and the 
Comprehensive Cancer Center to discuss patient cases for which one or more mutations had been found by NGS, in genes different from those related to drug approval (for example, a $B R A F$ mutation in a lung cancer, referred as "unreferenced genomic alteration" UGA), to make a decision if genetic alterations may be clinically relevant and targetable, in order to better select treatment for each patient.

In this paper, we evaluated the benefit of performing NGS-genomic screening in combination with MTB by comparing the output of NGS-genomic screening alone or in combination with MTB examining the identified UGA over two different time-periods 


\section{MATERIAL AND METHODS:}

The Molecular and Genetic Department of the University Hospital of Rennes, France, centralizes all samples from a population basin of around 3 million inhabitants, for the genomic testing of alterations used for the prescription of MTT, namely EGFR and $A L K$ for lung cancers, $K R A S, N R A S$ and $B R A F$ for colorectal cancers and $B R A F$ for melanoma, for which reimbursement of testing is available. In 2014, the results of NGS analysis, available to clinician were limited to the specific druggable alteration, additional genomic alteration not related to the prescription of an authorized drug (referred thereafter as UGA, "unreferenced genomic alteration") were not available to clinicians. Since 2015, all UGA were discussed in MTB and since January 2016, UGA were discussed only if clinicians propose the case to discussion, because of its clinical relevance. We thus consider two different time-periods: 2014 without MTB and 2015-2016 with MTB.

\section{Molecular Tumor Board organization:}

The MTB is a multi-disciplinary board composed of clinicians, oncologists, radiotherapists, radiologists, biologists, pathologists, and scientists with expertise in cancer genetics, molecular biology and drug-target. Each month, 5 to 10 patients from the University Hospitals and the Comprehensive Cancer Center were discussed. Clinician described first each patient-cases with demographics parameters (age, sex, performance status), comorbidities, clinical history (diagnosis and date of diagnosis, all treatments received, dates and responses). The biologists gave the molecular characteristics of the alterations, their allele-frequency and if known their incidence to evaluate their potential impact on relevant pathways. Experts discuss and confront their vision regarding the relevance of the identified about the mutation, its potential role in oncogenesis and which targeted therapy could be used outside clinical trials based on prior evidence, or if clinical trials could be proposed. MTT were only proposed if medical committee considered scientific evidences of efficacy sufficient. The committee provides a therapeutic decision for each case following referral recommendations, the availability of clinical trials and ethical considerations (as shown in Figure 1):

-“a clinical trial with appropriate MTT”,

-“an MTT approved in another indication, guided by the molecular alteration"

-“no implication of the genomic alteration".

\section{Molecular testing:}


All testing were performed at the at the Molecular and Genetic Department of the University Hospital of Rennes, France. DNA was extracted from the paraffin embedded tumor sample, then NGS analysis was done. Since 2014, the panels choose by the platform evolved; in 2014, 2015 and 2016, 18, 20 and 31 genes were respectively analyzed. Only mutations were considered in these panels, without analysis of fusion or amplification:

- In 2014: BRAF exons 11 and 15, EGFR exons 18, 19, 20 and 21, ERBB2 exon 20, KRAS exons 2, 3 and 4, NRAS exons 2,3 et 4, KIT exons 8, 9,11, 13, 14, 17 and 18, PDGFRA exons 12, 14, 18, PIK3CA exons 10 and 21, ALK exons 22, 23, 24, 25, 26, 29, MET exons 2, 14, 16, 17, 18, 19, 20, CTNNB1 exon 3, IDH1 exon 4, IDH2 exon 4, HRAS exons 2, 3, 4, MAP2K1 exons 2, 3, 6, 7, 11, AKT1 exons 3 and 4, FGFR3 exons 7, 9, 14, 16, ERBB4 exons 10 and 12.

- In 2015: BRAF exons 11 and 15, EGFR exons 18, 19, 20 and 21, ERBB2 exon 20, KRAS exons 2, 3 and 4, NRAS exons 2,3 and 4, KIT exons 8, 9,11, 13, 14, 17 and 18, PDGFRA exons 12, 14, 18, PIK3CA exons 10 and 21, ALK exons 22, 23, 24, 25, 26, 29, MET exons 2, 14, 16, 17, 18, 19, 20, CTNNB1 exon 3, IDH1 exon 4, IDH2 exon 4, HRAS exons 2, 3, 4, MAP2K1 exons 2, 3, 6, 7, 11, AKT1 exons 3 and 4, ERBB4 exons 10 and 12, FGFR2 exons 7, 9, 12 and 14, FGFR3 exons 7, 9, 14, 16, PTEN exon 7.

- In 2016: BRAF exons 11 and 15, EGFR exons 18, 19, 20 and 21, ERBB2 exon 20, KRAS exons 2, 3 and 4, NRAS exons 2,3 and 4, KIT exons 8, 9,11, 13, 14, 17 and $18, P D G F R A$ exons 12, 14, 18, PIK3CA exons 10 and 21, ALK exons 22, 23, 24, 25, 26, 29, MET exons 2, 14, 16, 17, 18, 19, 20, CTNNB1 exon 3, GNA11 exon 5, GNAQ exon 4,IDH1 exon 4, IDH2 exon 4, H3F3A exon 2, HISTH3B exon 1, TERT, HRAS exons 2, 3, 4, MAP2K1 exons 2, 3, 6, 7, 11, MAPK1 exons 1, 2, 3, 4, 7, MAPK3 exons 2, 3, 4, $R A C 1$ exon 2, ROS1 exon 38, AKT1 exons 3 and 4, ERBB4 exons 10 and 12, FGFR2 exons 7, 9, 12 and 14, FGFR3 exons 7, 9, 14, 16, MITF exons 10 and 12, PTEN exon 7, TYRP1 exon 8.

All testing were performed at the molecular and genetic platform in University Hospital in Rennes. Samples were previously histologically reviewed and pathologists evaluated percentage of tumour cells and necrosis. DNA was extracted from various routine paraffin embedded tumor sample (FFPE) samples using the MagDEA DNA 200 kit (Precision System Science, Japan) and quantitated with the Quan-iT PicoGreen dsDNA assay kit (Invitrogen) according to the manufacturer's instruction. A panel of primers targeting clinically relevant cancer genes was design by Rennes laboratory with a target size range of 120-145bp. Targets amplification was performed using the Access Array System (Fluidigm) and purified libraries were sequenced with the MiSeq (Illumina). Data were analyzed using house bioinformatics pipeline. Variants were defined with a variant allele 
frequency (VAF) higher than 5\% and a coverage beyond than 600 reads. All mutations described like "benign" or "polymorphism" by variant annotation tools was not reported.

\section{RESULTS:}

The flow chart is reported in Figure 2. In 2014, 590 patients were tested by NGS, and 86 had UGA. During 2015 and 2016, 1337 patients were tested, and 113 were discussed in MTB. Patient characteristics are reported in

Table 1. The most frequent tumor types are in 2014 and 2015-2016: lung cancer (respectively $n=24$ and $n=41$ ), colorectal cancer (respectively $n=30$ and $n=13$ ) and melanoma (respectively $n=13$ and $n=31$ ).

The patients' clinical characteristics presented at the MTB are presented Table 2. Median age of patients was 59 years. Most patients (48\%) had Performance Status (PS) ranging from 0,1 to 2. 45\% patients were in first line of treatment.

\section{Genomic results:}

For our whole cohort, the most frequent molecularly altered genes discussed at our MTB were in 2014: PIK3CA $(\mathrm{n}=29), \operatorname{KRAS}(\mathrm{n}=18), \operatorname{CTNNB1}(\mathrm{n}=12), B R A F(\mathrm{n}=10)$ and HRAS $(\mathrm{n}=9)$; whereas in 2015-2016, they were: $\operatorname{KRAS}(\mathrm{n}=26), N R A S(\mathrm{n}=21), P I K 3 C A(\mathrm{n}=16), B R A F(\mathrm{n}=18), E G F R(\mathrm{n}=10), C T N N B 1(\mathrm{n}=9)$, and $M E T(\mathrm{n}=11)$.

\section{Treatment decisions:}

During 2015 and 2016, for the 113 patients discussed, MTB proposed a MTT for 48 patients (42.5\%), including for 30 patients $(26.5 \%)$ in a clinical trial. Among the 48 propositions of MTT, only $14(29.2 \%)$ had an implication at the moment of the MTB, $30(62.5 \%)$ were for considering UGA at the relapse and $4(8.3 \%)$ were for representation at MTB after relapse when no more therapeutic options would be available. Two patients with an UGA were included in a clinical trial with a MTT targeting the UGA in 2015-2016, versus none in 2014 $(\mathrm{p}=0.22) .13$ patients with an UGA $(11.5 \%)$ were treated in 2015-2016 with a MTT (including the 2 patients treated within a clinical trial) versus none in $2014(\mathrm{p}=0.001)$. The main reasons for not providing MTT after MTB were no available clinical trial or no known drugs targeting the UGA in 30 patients $(46.2 \%)$, UGA of unknown significance in 8 patients (12.3\%), UGA known to be a mutation of resistance in $6(9.2 \%)$, clinical setting with no indication of MTT in $11(16.9 \%)$ and finally diverse reasons in 10 patients $(15.4 \%)$. Among the 30 propositions of MTT at relapse, 5 patients had not progressed yet, 8 patients were dead or unfit for treatment, 
for 4 patients, clinicians did not want to propose MTT because of a better alterative treatment (for example: immunotherapy in lung cancer) and one patient refused MTT.

\section{$\underline{\text { Treatment results: }}$}

Patients treated with a therapy targeting a mutation of sensibility are presented in Table 3. Among them, 2 patients were included in a clinical trial (NCT02304809 and NCT02034981), 3 patients with a colorectal cancer in an adjuvant setting treated with aspirin in the context of $P I K 3 C A$ mutations (19), 3 patients with an UGA were treated with a MTT outside a clinical trial (10,20,21): a KIT-mutated melanoma had clinical benefit of imatinib during 9 months, whereas NSCLC (Non-small cell lung cancer) with $A L K$ mutation or insertion on ERBB2 gene were treated only one month with MTT.

Patients with resistance mutations were also treated with MTT, due to the absence of alternative therapies at that time and the lack of literature on these mutations (22-25); most of them were treated with a MTT for less than 3 months. Results are presented in Table 4. 


\section{DISCUSSION:}

Here we measured the utility of MTB in clinical daily practice, by comparing two period-time: panelgenomic screening using NGS and the discussion or not of the identified UGA. With these period-time restrospective cohorts, we showed that the association of panel-genomic testing and MTB is feasible in daily practice and increases significantly the prescription of MTT. We however identified the limitation for inclusion in clinical trials.

Despite recommendations of the MTB, most of patients did not received MTT or were not included in clinical trial. Among 113 patients, the MTB recommended MTT for 48 patients (42.5\%), and only 13 patients (11.5\%) were treated with MTT. Clinical trials were proposed for 30 patients $(26.5 \%)$, but only 2 patients $(1.8 \%)$ were actually included. Different explanations could be proposed to explain such low proportion of patients treated with MTT. First, due to our recruitment by clinical routine diagnosis, most of our patients were in first line of treatment $(45 \%)$, non metastatic $(25 \%)$ or in complete response $(12 \%)$, with no need for immediate systemic treatment. In contrast, the SHIVA trial (7) required progression on all treatment approved for their localization before inclusion; half of their population were in $3^{\text {rd }}$ or $4^{\text {th }}$ line of treatment. As a consequence for our patients in early lines of treatment, among 48 propositions of MTT, only one third had an implication at the moment of the MTB, whereas $60 \%$ were to be considered only in case of cancer relapse. In some cases, even in the case of relapse, there are better options that a single targeted therapy, such as immunotherapy for BRAF-mutated NSCLC instead of inclusion in the AcSé vemurafenib basket trial.

Second, due to exclusion criteria, some patients were ineligible for clinical trial. Finally, and probably most importantly, we often found mutations without any authorized drug targeting these alterations nor clinical trial available for these UGA. To increase inclusion in clinical trials, we could establish a systematic proposition of inclusion in recruiting clinical trial targeting the UGA.

Other teams reported their experience of MTB as well as their rate of acceptance of MTB-decision; only $25 \%$ of recommendations of the MTB at Darmouth-Hitchcock Medical Center were followed (26); a team from the Dijon Center, reported that only $18 \%$ of patients received the MTT recommended by the MTB (10). A multicentric prospective trial, Profiler(27) had similar rates; 2579 patients were screened in four centers, a MTT was recommended for $27 \%$ patients, and only 163 patients (6\%) were treated with MTT. These results are similar to ours. 
If we excluded patients treated with MTT on resistance mutation and patients treated in adjuvant setting, two patients (15\%) had a clinical benefit from MTT. In Profiler trial (27), the overall response rate is $0.09 \%$ for the whole cohort. In advanced non-small cell cancer, large-scale genomic sequencing compare to routine testing EGFR or ALK rearrangement is not associated with better survival(28). In MOSCATO trial 33\% of patients treated with a MTT improve clinical outcomes as defined by their primary endpoint of increase by 1.3 of PFS (5), with an overall response rate of $11 \%$. MOSCATO trial was in fact conducted at Gustave Roussy, where clinicians have access to many clinical trials, especially early phases that can broaden the spectrum of MTT available; indeed, $75 \%$ of patients treated with MTT in MOSCATO trial were included in phase I/II trials.

In our cohort, five patients were treated with MTT despite alterations known to confer resistance, due to the absence of any alternative therapy. Moreover, some of these mutations are uncertain as to whether they really confer resistance, but were different from those published as not being responsible for resistance (23). NGS analysis could explain some resistance to targeted therapy, and in our example of $B R A F$ co-mutated melanoma could have allow redirecting patients toward immunotherapy instead of MTT.

Our study demonstrated the feasibility of implementing personalized medicine in the routine setting. Patients now discussed in our MTB are treated in all centers of Brittany, and could benefit from an expert discussion. We also recently organized an inter-regional network of institutions participating in early phase trials: ARPEGO (Accès à la Recherche Précoce et Innovante dans la region Grand Ouest). This network, combined with the MTB, could increase the probability to match patients and trials, according to the molecular abnormalities of their tumors. There is thus a strong need to better select patients who would benefit from this personalized medicine. We hope that continuation of the strategy with a regional coordination to offer access to clinical trials (ARPEGO network) will improve access of patients to active MTT.

Another way to improve the MTB, could be the discussion of patients with evaluation of tumor mutation burden (TMB) by NGS $(29,30)$, in order to select the best responders to immunotherapy. Indeed, despite the significant success of immunotherapy, the therapeutic efficacy varies greatly from one to another patient (31). High PDL-1 expression has linked to improved response to immune checkpoint inhibitors, but immunohistochemistry scoring 
can be variable, and some patients with low PDL-1 expression could have benefit from immune checkpoint inhibitors. TMB is an promising emerging independent biomarker of immune checkpoint inhibitors (32-35). 


\section{CONCLUSION:}

This report of our experience using the association of NGS panel within a multidisciplinary MTB showed that this approach is feasible in a routine setting. Despite a regional organization, we offered a therapeutic change in only $11.5 \%$ of patients discussed at the MTB; there is a need to select patient who would benefit from this personalized medicine. By implementing tumor mutational load data in the data discussed in our MTB, prediction of responders to immune checkpoint inhibitors could be one of the future aims. 


\section{CONFLICT OF INTEREST:}

The authors declare that they have no conflict of interest 


\section{BIBLIOGRAPHY:}

1. Hauschild A, Grob J-J, Demidov LV, Jouary T, Gutzmer R, Millward M, et al. Dabrafenib in BRAF-mutated metastatic melanoma: a multicentre, open-label, phase 3 randomised controlled trial. Lancet Lond Engl. 28 juill 2012;380(9839):358-65.

2. Chapman PB, Hauschild A, Robert C, Haanen JB, Ascierto P, Larkin J, et al. Improved survival with vemurafenib in melanoma with BRAF V600E mutation. N Engl J Med. 30 juin 2011;364(26):2507-16.

3. Robert C, Karaszewska B, Schachter J, Rutkowski P, Mackiewicz A, Stroiakovski D, et al. Improved Overall Survival in Melanoma with Combined Dabrafenib and Trametinib [Internet]. http://dx.doi.org/10.1056/NEJMoa1412690. 2014 [cité 19 nov 2017]. Disponible sur: http://www.nejm.org/doi/full/10.1056/NEJMoa1412690

4. $\quad$ Pagès A, Foulon S, Zou Z, Lacroix L, Lemare F, de Baère T, et al. The cost of molecular-guided therapy in oncology: a prospective cost study alongside the MOSCATO trial. Genet Med Off J Am Coll Med Genet. 1 déc 2016;

5. Massard C, Michiels S, Ferté C, Le Deley M-C, Lacroix L, Hollebecque A, et al. HighThroughput Genomics and Clinical Outcome in Hard-to-Treat Advanced Cancers: Results of the MOSCATO 01 Trial. Cancer Discov. juin 2017;7(6):586-95.

6. André F, Bachelot T, Commo F, Campone M, Arnedos M, Dieras V, et al. Comparative genomic hybridisation array and DNA sequencing to direct treatment of metastatic breast cancer: a multicentre, prospective trial (SAFIR01/UNICANCER). Lancet Oncol. mars 2014;15(3):267-74.

7. Le Tourneau C, Kamal M, Tsimberidou A-M, Bedard P, Pierron G, Callens C, et al. Treatment Algorithms Based on Tumor Molecular Profiling: The Essence of Precision Medicine Trials. J Natl Cancer Inst. avr 2016;108(4).

8. Schwaederle M, Zhao M, Lee JJ, Lazar V, Leyland-Jones B, Schilsky RL, et al. Association of Biomarker-Based Treatment Strategies With Response Rates and Progression-Free Survival in Refractory Malignant Neoplasms: A Meta-analysis. JAMA Oncol. 6 juin 2016;

9. Knepper TC, Bell GC, Hicks JK, Padron E, Teer JK, Vo TT, et al. Key Lessons Learned from Moffitt's Molecular Tumor Board: The Clinical Genomics Action Committee Experience. The Oncologist. févr 2017;22(2):144-51.

10. Kaderbhai CG, Boidot R, Beltjens F, Chevrier S, Arnould L, Favier L, et al. Use of dedicated gene panel sequencing using next generation sequencing to improve the personalized care of lung cancer. Oncotarget. 26 mars 2016;7(17):24860-70.

11. Harada S, Arend R, Dai Q, Levesque JA, Winokur TS, Guo R, et al. Implementation and utilization of the molecular tumor board to guide precision medicine. Oncotarget. 22 août 2017;8(34):57845-54.

12. Beltran H, Eng K, Mosquera JM, Sigaras A, Romanel A, Rennert H, et al. WholeExome Sequencing of Metastatic Cancer and Biomarkers of Treatment Response. JAMA Oncol. juill 2015;1(4):466-74.

13. Laskin J, Jones S, Aparicio S, Chia S, Ch'ng C, Deyell R, et al. Lessons learned from the application of whole-genome analysis to the treatment of patients with advanced cancers. Cold Spring Harb Mol Case Stud. oct 2015;1(1):a000570.

14. Parker BA, Schwaederlé M, Scur MD, Boles SG, Helsten T, Subramanian R, et al. 
Breast Cancer Experience of the Molecular Tumor Board at the University of California, San Diego Moores Cancer Center. J Oncol Pract. nov 2015;11(6):442-9.

15. Ortiz MV, Kobos R, Walsh M, Slotkin EK, Roberts S, Berger MF, et al. Integrating Genomics Into Clinical Pediatric Oncology Using the Molecular Tumor Board at the Memorial Sloan Kettering Cancer Center. Pediatr Blood Cancer. 2016;63(8):1368-74.

16. Blasinska-Morawiec M, Tubiana-Mathieu N, Fougeray R, Pinel M-C, Bougnoux P. Phase II study of intravenous vinflunine after failure of first-line vinorelbine based regimen for advanced breast cancer. Breast Edinb Scotl. févr 2013;22(1):58-63.

17. Basse C, Morel C, Alt M, Sablin MP, Franck C, Pierron G, et al. Relevance of a molecular tumour board (MTB) for patients' enrolment in clinical trials: experience of the Institut Curie. ESMO Open [Internet]. 6 avr 2018 [cité 28 oct 2018];3(3). Disponible sur: https://www.ncbi.nlm.nih.gov/pmc/articles/PMC5890857/

18. Rolfo C, Manca P, Salgado R, Van Dam P, Dendooven A, Machado Coelho A, et al. Multidisciplinary molecular tumour board: a tool to improve clinical practice and selection accrual for clinical trials in patients with cancer. ESMO Open [Internet]. 23 juill 2018 [cité 28 oct 2018];3(5). Disponible sur:

https://www.ncbi.nlm.nih.gov/pmc/articles/PMC6069914/

19. Liao X, Lochhead P, Nishihara R, Morikawa T, Kuchiba A, Yamauchi M, et al.

Aspirin use, tumor PIK3CA mutation, and colorectal-cancer survival. N Engl J Med. 25 oct 2012;367(17):1596-606.

20. Guo J, Si L, Kong Y, Flaherty KT, Xu X, Zhu Y, et al. Phase II, open-label, single-arm trial of imatinib mesylate in patients with metastatic melanoma harboring c-Kit mutation or amplification. J Clin Oncol Off J Am Soc Clin Oncol. 20 juill 2011;29(21):2904-9.

21. Carvajal RD, Antonescu CR, Wolchok JD, Chapman PB, Roman R-A, Teitcher J, et al. KIT as a therapeutic target in metastatic melanoma. JAMA. 8 juin

2011;305(22):2327-34.

22. Tu H-Y, Ke E-E, Yang J-J, Sun Y-L, Yan H-H, Zheng M-Y, et al. A comprehensive review of uncommon EGFR mutations in patients with non-small cell lung cancer. Lung Cancer Amst Neth. déc 2017;114:96-102.

23. Shi H, Moriceau G, Kong X, Koya RC, Nazarian R, Pupo GM, et al. Preexisting MEK1 exon 3 mutations in V600E/KBRAF melanomas do not confer resistance to BRAF inhibitors. Cancer Discov. mai 2012;2(5):414-24.

24. Watson IR, Li L, Cabeceiras PK, Mahdavi M, Gutschner T, Genovese G, et al. The RAC1 P29S hotspot mutation in melanoma confers resistance to pharmacological inhibition of RAF. Cancer Res. 1 sept 2014;74(17):4845-52.

25. Nikolaev SI, Rimoldi D, Iseli C, Valsesia A, Robyr D, Gehrig C, et al. Exome sequencing identifies recurrent somatic MAP2K1 and MAP2K2 mutations in melanoma. Nat Genet. 25 déc 2011;44(2):133-9.

26. Tafe LJ, Gorlov IP, de Abreu FB, Lefferts JA, Liu X, Pettus JR, et al. Implementation of a Molecular Tumor Board: The Impact on Treatment Decisions for 35 Patients Evaluated at Dartmouth-Hitchcock Medical Center. The Oncologist. sept 2015;20(9):1011-8.

27. Trédan $\mathrm{O}$, Wang $\mathrm{Q}$, Pissaloux $\mathrm{D}$, Cassier $\mathrm{P}$, de la Fouchardière A, Fayette J, et al. Molecular screening program to select molecular-based recommended therapies for metastatic cancer patients: analysis from the ProfiLER trial. Ann Oncol Off J Eur Soc Med Oncol. 13 mars 2019;

28. Presley CJ, Tang D, Soulos PR, Chiang AC, Longtine JA, Adelson KB, et al. Association of Broad-Based Genomic Sequencing With Survival Among Patients With 
Advanced Non-Small Cell Lung Cancer in the Community Oncology Setting. JAMA. 07 2018;320(5):469-77.

29. Chalmers ZR, Connelly CF, Fabrizio D, Gay L, Ali SM, Ennis R, et al. Analysis of 100,000 human cancer genomes reveals the landscape of tumor mutational burden. Genome Med. 19 2017;9(1):34.

30. Zehir A, Benayed R, Shah RH, Syed A, Middha S, Kim HR, et al. Mutational landscape of metastatic cancer revealed from prospective clinical sequencing of 10,000 patients. Nat Med. juin 2017;23(6):703-13.

31. Nishino M, Ramaiya NH, Hatabu H, Hodi FS. Monitoring immune-checkpoint blockade: response evaluation and biomarker development. Nat Rev Clin Oncol. nov 2017;14(11):655-68.

32. Yarchoan M, Hopkins A, Jaffee EM. Tumor Mutational Burden and Response Rate to PD-1 Inhibition. N Engl J Med. 21 2017;377(25):2500-1.

33. Van Allen EM, Miao D, Schilling B, Shukla SA, Blank C, Zimmer L, et al. Genomic correlates of response to CTLA-4 blockade in metastatic melanoma. Science. 9 oct 2015;350(6257):207-11.

34. Mismatch repair deficiency predicts response of solid tumors to PD-1 blockade. PubMed - NCBI [Internet]. [cité 13 oct 2018]. Disponible sur: https://www-ncbi-nlmnih-gov.passerelle.univ-rennes1.fr/pubmed/?

term=Mismatch+repair+deficiency+predicts+response+of+solid+tumors+to+PD$1+$ blockade

35. Rizvi NA, Hellmann MD, Snyder A, Kvistborg P, Makarov V, Havel JJ, et al. Cancer immunology. Mutational landscape determines sensitivity to PD-1 blockade in non-small cell lung cancer. Science. 3 avr 2015;348(6230):124-8. 


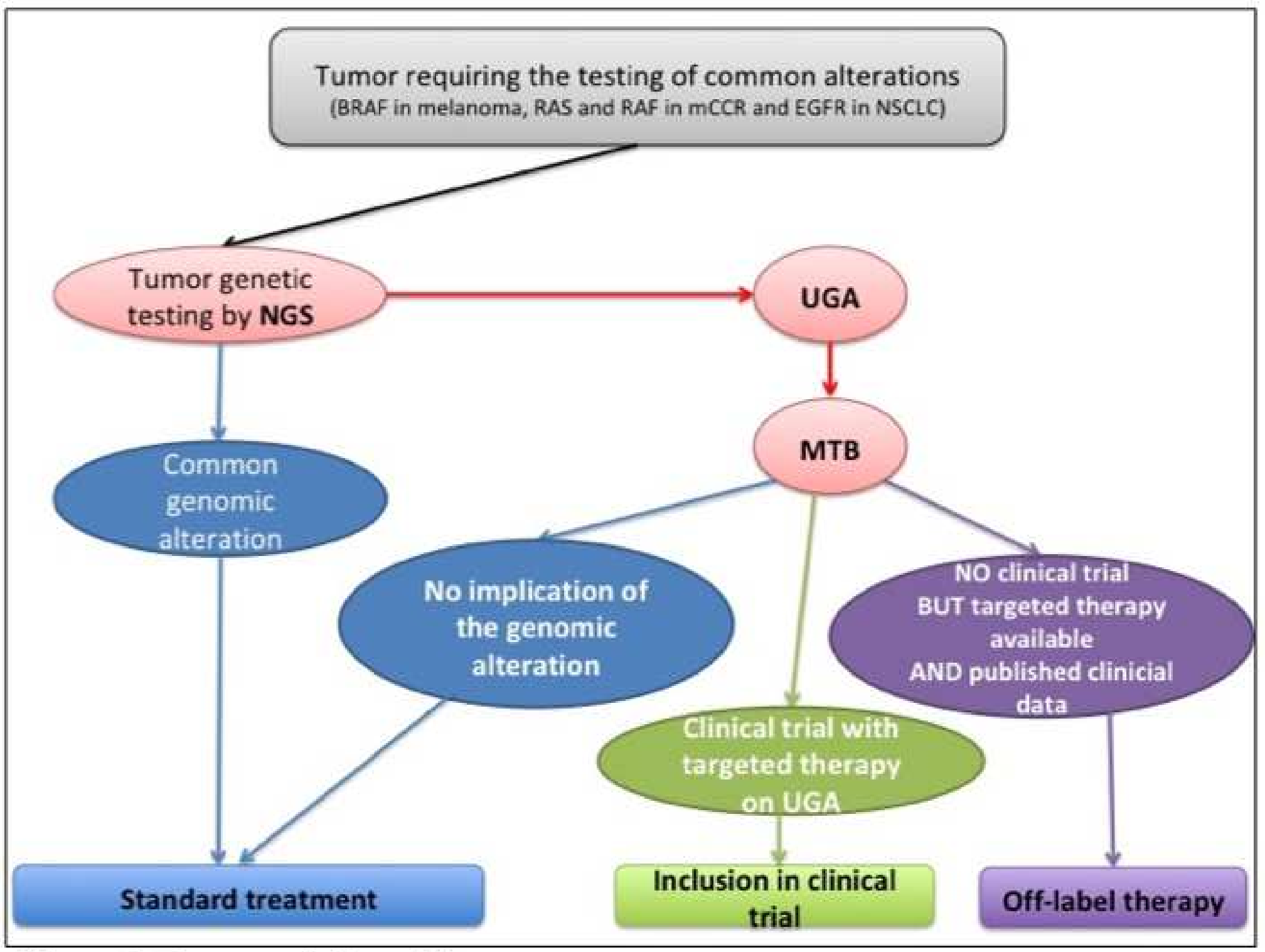

Figure 1: Tumor analysis workflow 


\section{In 2014}
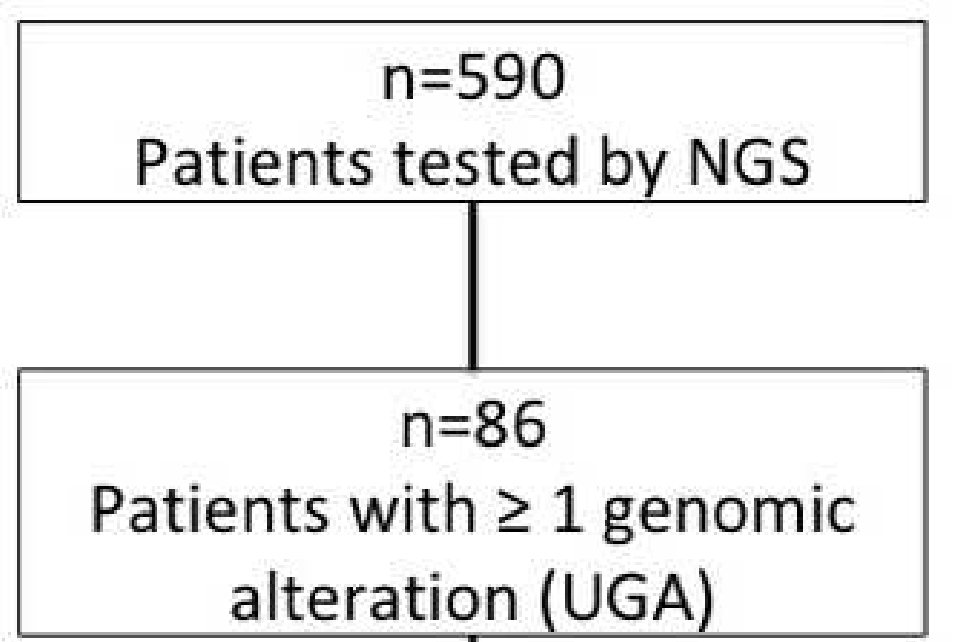

In 2015-2016
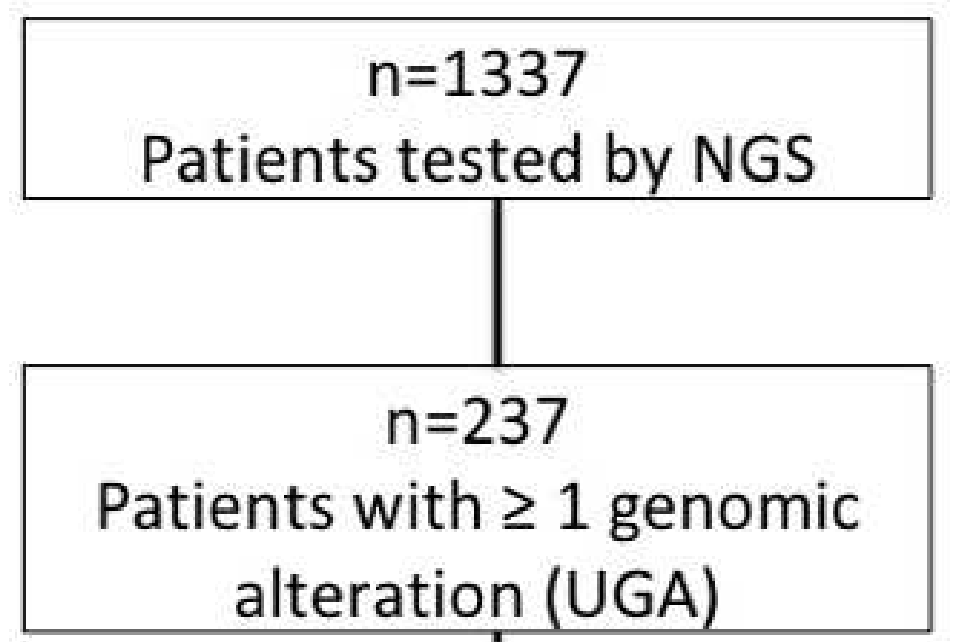

$$
n=113
$$

Patients presented at the MTB

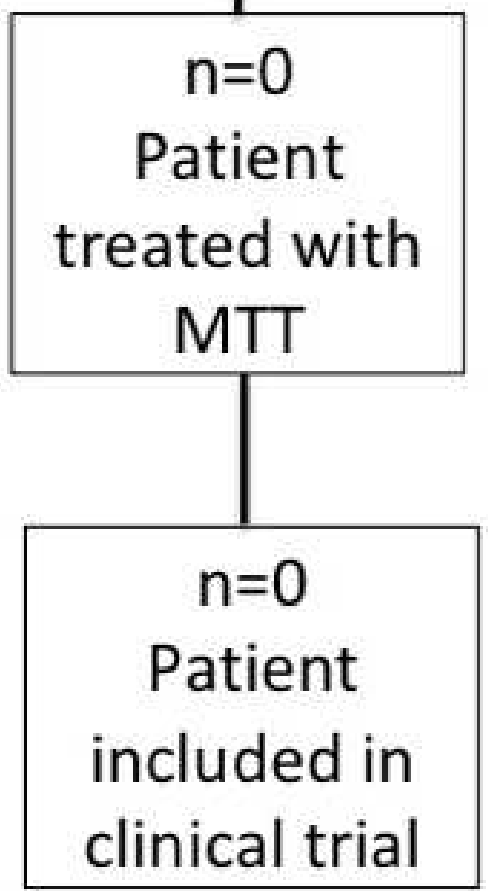

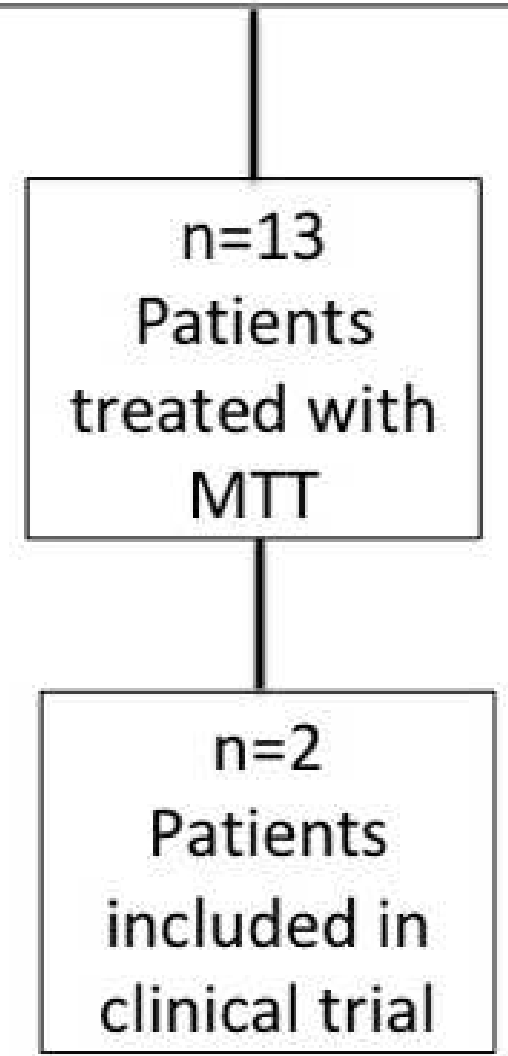


A

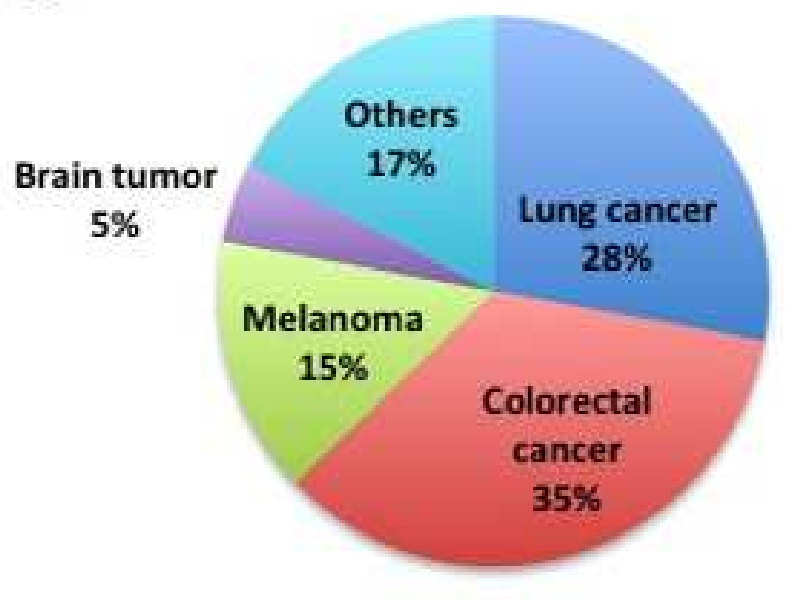

B

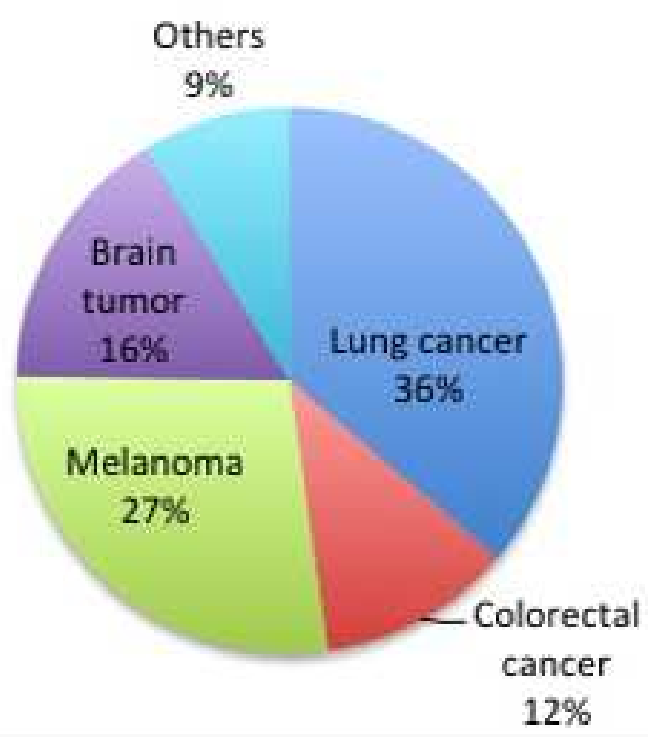

Figure 3: Tumor types for patients in 2014 (A) and 2015-2016 (B) 


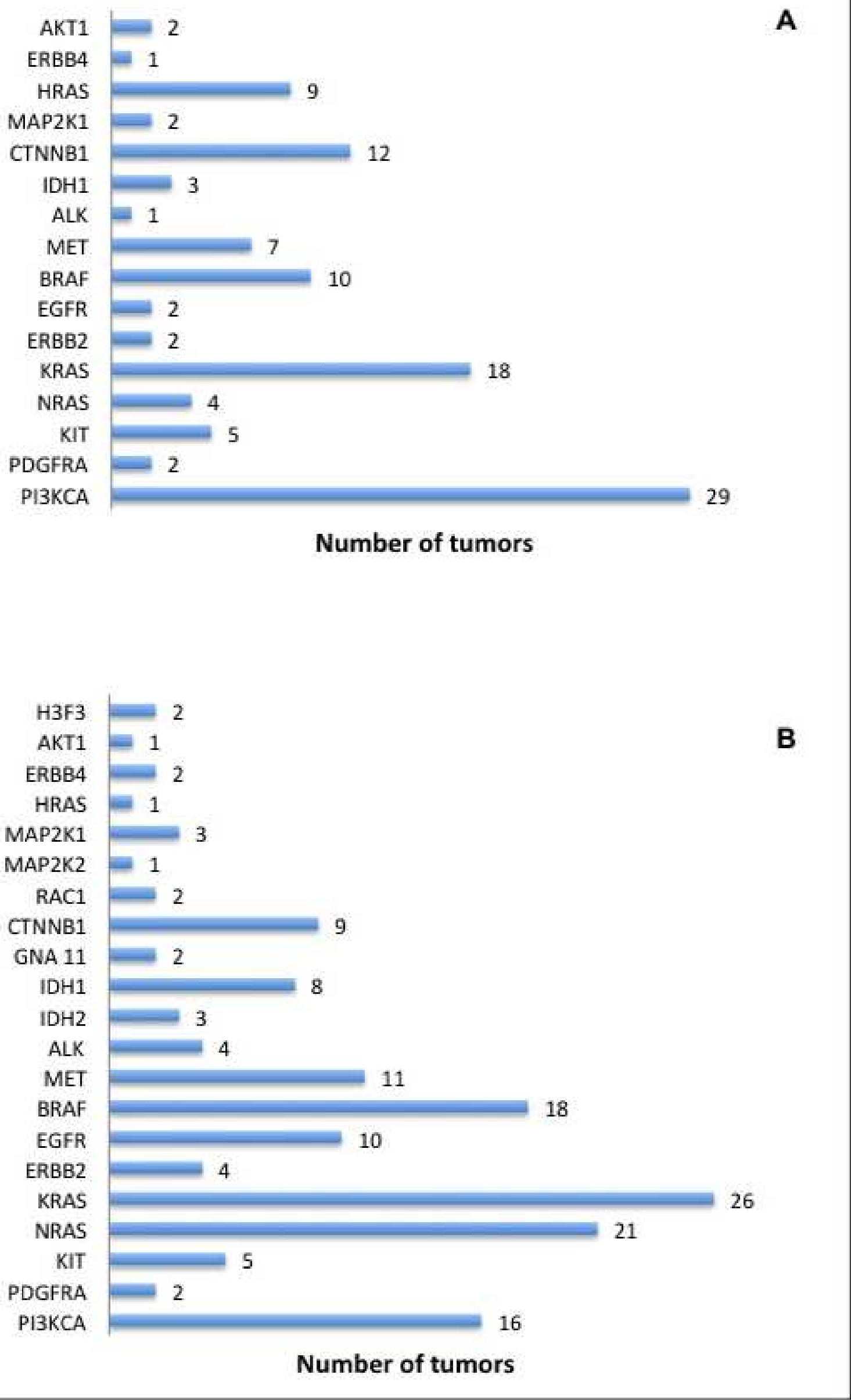

Figure 4: Patients' genomic alterations in 2014 (A) and 2015-2016 (B) 